IOS Press

\title{
Micropropagation in vitro of highbush blueberry (Vaccinium corymbosum L.) ${ }^{1}$
}

\author{
Djurdjina Ružića,*, Tatjana Vujovića ${ }^{\mathrm{a}}$, Gabriela Libiakova ${ }^{\mathrm{b}}$, Radosav Cerovića \\ and Alena Gajdošova ${ }^{\mathrm{b}}$ \\ ${ }^{a}$ Fruit Research Institute, Čačak, Serbia \\ ${ }^{\mathrm{b}}$ Institute of Plant Genetics and Biotechnology SAS, Nitra, Slovak Republic
}

Received 11 November 2011; accepted 19 November 2011

\begin{abstract}
Murashige and Skoog medium (MS) and modified Anderson's Rhododendron medium (mAN) were compared for in vitro shoot multiplication of three highbush blueberries 'Berkeley', 'Bluecrop' and 'Goldtraube'. All media contained $0.5 \mathrm{mg} 1^{-1}$ zeatin applied either alone or combined with $0.1,1$ and $5 \mathrm{mg}^{-1}$ IBA. In vitro rooting was induced using mAN medium supplemented with $0.8 \mathrm{mg} \mathrm{l}^{-1}$ IBA and $4 \mathrm{~g} \mathrm{l}^{-1}$ activated charcoal. The results obtained showed that mAN medium is more suitable for in vitro multiplication of the selected highbush blueberry cultivars than MS medium. Low concentration of IBA $\left(\leq 1 \mathrm{mg} 1^{-1}\right)$ added in zeatinsupplemented mAN medium increases shoot multiplication efficiency of highbush blueberries in vitro and can be recommended for large-scale propagation of high-quality plants. MS medium induced partial or full necrosis of stems and leaves, which was more pronounced on media containing zeatin combined with increasing concentration of IBA. Rooting capacity of shoots varied widely among the tested blueberry cultivars. The highest rooting and acclimatization rates were achieved in 'Goldtraube' (82.8\% and $91.8 \%$ respectively), and the lowest ( $10 \%$ and $66.7 \%$ respectively) were in 'Berkeley'.
\end{abstract}

Keywords: Highbush blueberry, nutritive media, multiplication, rooting, acclimatization

\section{Introduction}

Highbush blueberry (Vaccinium corymbosum L.) is most commonly cultivated, commercially important and biologically valuable species of the genus Vaccinium L. Fruits contain high level of vitamins, anthocyanins and other bioactive organic substances possessing antioxidant, anti-tumour and anti-inflammatory activities [1]. In recent years, due to the high nutritional value and health benefits of blueberries, there has been an increased interest in their production both among growers and consumers throughout the world. The production of high-quality plants required for the establishment of plantings presupposes the adoption of modern propagation techniques. Although generally successful in blueberries, conventional methods of vegetative propagation by softwood and hardwood cuttings are slow and labour intensive, and the results are variable among genotypes, age of stock plant and growing seasons. Also, traditional propagation methods are not particularly efficient as regards the number of propagules generated and production of healthy, pathogen-free planting material [2]. These limitations can be overcome by the application of in vitro techniques. Furthermore, tissue culture-propagated blueberries have greater plant spread (bearing area) and consequently higher yields in comparison with conventionally propagated plants from softwood, single-node cuttings [3]. Debnath [4] argued that enhanced vegetative growth of tissue culture blueberry plants may prove to be

\footnotetext{
${ }^{1}$ Paper presented at 28th International Horticulture Congress, IHC 2010, Lisbon, Portugal.

*Corresponding author: Djurdjina Ružić, Department for Fruit Physiology, Fruit Research Institute, Kralja Petra I 9,32000 Čačak, Serbia. Tel.: +381 32227 550; Fax: +381 32221 391; E-mail: jugvocca@yu1.net.
} 
beneficial to growers through establishing plants for an early fruit production and thus achieving improved return on investment.

In vitro propagation of blueberries through axillary branching system has been investigated over the past three decades. Most of the studies were concerned with the effect of various cytokinins and/or different basal media on shoot multiplication efficiency [5-11]. Systems of adventitious shoot regeneration from leaf explants of blueberry have also been reported for a number of cultivars [2, 12-15]. There were also few reports on application of different auxins in in vitro axillary and adventitious shoot development of blueberries [8, 15-18]. However, the results are not broadly applicable, since morphogenic response is highly genotype-dependent on plant growth regulators and media used for culturing [4].

The aim of this investigation was to develop an efficient protocol for micropropagation of different blueberry cultivars so as to ensure sufficient supply of healthy, pathogen-free planting material essential for the establishment and further development of intensive cultivation of blueberry in Serbia. Strictly, studies were conducted to compare two basal nutritive media of different hormonal composition used for axillary shoot multiplication of three highbush blueberry cultivars introduced from Slovakia.

\section{Materials and methods}

\subsection{Plant material}

Blueberry cultivars 'Berkeley', 'Bluecrop' and 'Goldtraube' were introduced from Slovakia (Institute of Plant Genetics and Biotechnology SAS, Nitra) to Serbia within the framework of bilateral project titled 'In vitro regeneration of highbush blueberry (Vaccinium corymbosum), determination of the genetic variability and development of in vitro transformation protocols'. Aseptic culture of these cultivars was established in Slovakia according to the procedure previously described by Ostrulucka et al. [14]. Shoots obtained in multiplication stage were brought into the Tissue Culture Laboratory of Fruit Research Institute, Čačak for further experiments.

\subsection{Effects of nutrient media and hormonal composition on shoot multiplication}

For the multiplication phase, two basal nutrient media, Murashige and Skoog (MS) medium [19] and modified Anderson's Rhododendron medium (mAN) were tested. Anderson's Rhododendron medium - AN medium [20] was modified as follows: $37.3 \mathrm{mg}^{-1} \mathrm{NaEDTA}$ and $27.8 \mathrm{mg}^{-1} \mathrm{FeSO}_{4} \times 7 \mathrm{H}_{2} \mathrm{O}$ were used instead of $73.40 \mathrm{mg}^{-1}$ FeNaEDTA. The media contained $0.5 \mathrm{mg}^{-1}$ zeatin applied alone or combined with different concentrations $(0.1,1$ and $5 \mathrm{mg} \mathrm{l}^{-1}$ ) of indole-3-butyric acid (IBA) (Table 1). All the media contained $30 \mathrm{~g} \mathrm{l}^{-1}$ sucrose and $8 \mathrm{~g} \mathrm{l}^{-1}$ agar, $\mathrm{pH}$ value being adjusted to 4.8 before autoclaving. Zeatin was filter sterilised (Millipore filter, $0.22 \mu \mathrm{m}$ ) and added to the media upon autoclaving.

Uniform single shoots excised from the established cultures were used in multiplication experiments. Shoots were subcultured twice on each medium, and multiplication parameters were determined upon second subculture ( 35 days subculture interval). The multiplication parameters monitored were multiplication index and length of axial and lateral shoots. The multiplication index was defined as number of newly formed shoots $(>0.5 \mathrm{~cm})$ per initial shoot tip recorded after the stated subculture interval.

Cultures were maintained in growth chamber at $23 \pm 1^{\circ} \mathrm{C}$, under 16-h photoperiod. Light intensity, supplied by cool white fluorescent tubes, was $54 \mu \mathrm{mol} \mathrm{m}^{-2} \mathrm{~s}^{-1}$.

\subsection{Rooting and acclimatization}

Shoots of all the cultivars were rooted on modified AN medium supplemented with $0.8 \mathrm{mg} \mathrm{l}^{-1}$ IBA and $4 \mathrm{~g} \mathrm{1^{-1 }}$ activated charcoal. Percentage of the rooted plants as well as the other rooting parameters, such as number and length of roots and height of the rooted plants, were determined after 28 days. Both rooted and non-rooted shoots were removed from culture vessels, washed carefully with water to remove adhering medium, transferred to plastic pots containing sterile soil substrate and acclimatized on a 'mist' bench in greenhouse for two weeks. 
Table 1

Effect of basal medium and hormonal composition on multiplication parameters in different blueberry cultivars after 35 days of culturing

\begin{tabular}{|c|c|c|c|c|c|}
\hline Cultivar & Basal medium & $\begin{array}{l}\text { Growth regulator } \\
\text { combination }\left(\mathrm{mg} \mathrm{l}^{-1}\right)\end{array}$ & $\begin{array}{l}\text { Multiplication } \\
\text { index }\end{array}$ & $\begin{array}{c}\text { Length of } \\
\text { axial shoot }(\mathrm{cm})\end{array}$ & $\begin{array}{c}\text { Length of lateral } \\
\text { shoots }(\mathrm{cm})\end{array}$ \\
\hline \multirow[t]{8}{*}{ 'Berkeley' } & \multirow[t]{4}{*}{$\mathrm{mAN}$} & zeatin $(0.5)$ & $2.00 \mathrm{~b}^{1}$ & $2.01 \mathrm{~b}$ & $0.98 \mathrm{bc}$ \\
\hline & & zeatin $(0.5)+\operatorname{IBA}(0.1)$ & $2.21 \mathrm{a}$ & $2.32 \mathrm{a}$ & $1.14 \mathrm{~b}$ \\
\hline & & zeatin $(0.5)+$ IBA $(1)$ & $1.92 \mathrm{~b}$ & $2.23 \mathrm{ab}$ & $1.61 \mathrm{a}$ \\
\hline & & zeatin $(0.5)+$ IBA $(5)$ & $1.00 \mathrm{e}$ & $1.75 \mathrm{c}$ & - \\
\hline & \multirow[t]{4}{*}{ MS } & zeatin $(0.5)$ & $1.42 \mathrm{c}$ & $1.38 \mathrm{~d}$ & $0.81 \mathrm{c}$ \\
\hline & & zeatin $(0.5)+\operatorname{IBA}(0.1)$ & $1.22 \mathrm{~d}$ & $1.33 \mathrm{~d}$ & $0.85 \mathrm{c}$ \\
\hline & & zeatin $(0.5)+$ IBA $(1)$ & $1.09 \mathrm{de}$ & $1.51 \mathrm{~d}$ & $0.70 \mathrm{c}$ \\
\hline & & zeatin $(0.5)+$ IBA $(5)$ & $1.00 \mathrm{e}$ & $1.46 \mathrm{~d}$ & - \\
\hline \multirow[t]{8}{*}{ 'Bluecrop' } & \multirow[t]{4}{*}{$\mathrm{mAN}$} & zeatin $(0.5)$ & $2.12 \mathrm{~b}$ & $1.77 \mathrm{~b}$ & $1.04 \mathrm{ab}$ \\
\hline & & zeatin $(0.5)+$ IBA $(0.1)$ & $2.50 \mathrm{a}$ & $1.69 \mathrm{~b}$ & $0.89 \mathrm{bc}$ \\
\hline & & zeatin $(0.5)+$ IBA $(1)$ & $1.62 \mathrm{c}$ & $2.08 \mathrm{a}$ & $1.20 \mathrm{a}$ \\
\hline & & zeatin $(0.5)+$ IBA (5) & $1.25 \mathrm{~d}$ & $1.77 \mathrm{~b}$ & $0.77 \mathrm{c}$ \\
\hline & \multirow[t]{4}{*}{ MS } & zeatin $(0.5)$ & $1.88 \mathrm{bc}$ & $1.29 \mathrm{c}$ & $0.91 \mathrm{bc}$ \\
\hline & & zeatin $(0.5)+$ IBA $(0.1)$ & $1.79 \mathrm{c}$ & $1.36 \mathrm{c}$ & $0.95 \mathrm{bc}$ \\
\hline & & zeatin $(0.5)+$ IBA $(1)$ & $1.26 \mathrm{~d}$ & $1.46 \mathrm{c}$ & $0.83 \mathrm{bc}$ \\
\hline & & zeatin $(0.5)+$ IBA $(5)$ & $1.00 \mathrm{e}$ & $1.37 \mathrm{c}$ & - \\
\hline \multirow[t]{8}{*}{ 'Goldtraube' } & \multirow[t]{4}{*}{$\mathrm{mAN}$} & zeatin $(0.5)$ & $2.37 \mathrm{ab}$ & $1.77 \mathrm{c}$ & $0.96 \mathrm{bc}$ \\
\hline & & zeatin $(0.5)+\operatorname{IBA}(0.1)$ & $2.21 \mathrm{ab}$ & $2.30 \mathrm{a}$ & $1.19 \mathrm{ab}$ \\
\hline & & zeatin $(0.5)+$ IBA $(1)$ & $2.42 \mathrm{a}$ & $2.41 \mathrm{a}$ & $1.31 \mathrm{a}$ \\
\hline & & zeatin $(0.5)+$ IBA $(5)$ & $1.70 \mathrm{c}$ & $2.03 \mathrm{~b}$ & $1.22 \mathrm{ab}$ \\
\hline & \multirow[t]{4}{*}{ MS } & zeatin $(0.5)$ & $2.05 \mathrm{~b}$ & $1.77 \mathrm{c}$ & $1.04 \mathrm{abc}$ \\
\hline & & zeatin $(0.5)+\operatorname{IBA}(0.1)$ & $1.50 \mathrm{c}$ & $1.54 \mathrm{~cd}$ & $0.88 \mathrm{c}$ \\
\hline & & zeatin $(0.5)+$ IBA $(1)$ & $1.00 \mathrm{~d}$ & $1.50 \mathrm{~d}$ & - \\
\hline & & zeatin $(0.5)+$ IBA $(5)$ & $1.00 \mathrm{~d}$ & $1.32 \mathrm{~d}$ & - \\
\hline
\end{tabular}

${ }^{1}$ Mean values of multiplication parameters within each column followed by the same letter are not significantly different according to Duncan's Multiple Range Test $(P<0.05)$; mAN - modified Anderson's Rhododendron medium; MS - Murashige and Skoog medium.

\subsection{Statistical analysis}

In the multiplication experiment, each treatment included 6 culture vessels $\times 5$ uniform shoots $\times 2$ replications. The data were analysed by ANOVA and subsequently by the Duncan's Multiple Range Test for mean separation.

\section{Results and discussion}

The results obtained showed that mAN medium is more suitable for in vitro multiplication of selected highbush blueberry cultivars than MS medium (Table 1). Shoots multiplied on MS exhibited lower multiplication rate and poorer growth than those on the mAN media of the same hormonal composition. Debnath [21] also proved that media with low ionic concentrations are suitable for Vaccinium culture. The media most frequently used for highbush blueberry propagation are AN medium [2, 9, 14] and Woody Plant Medium - WPM [7, 8, 22]. The 

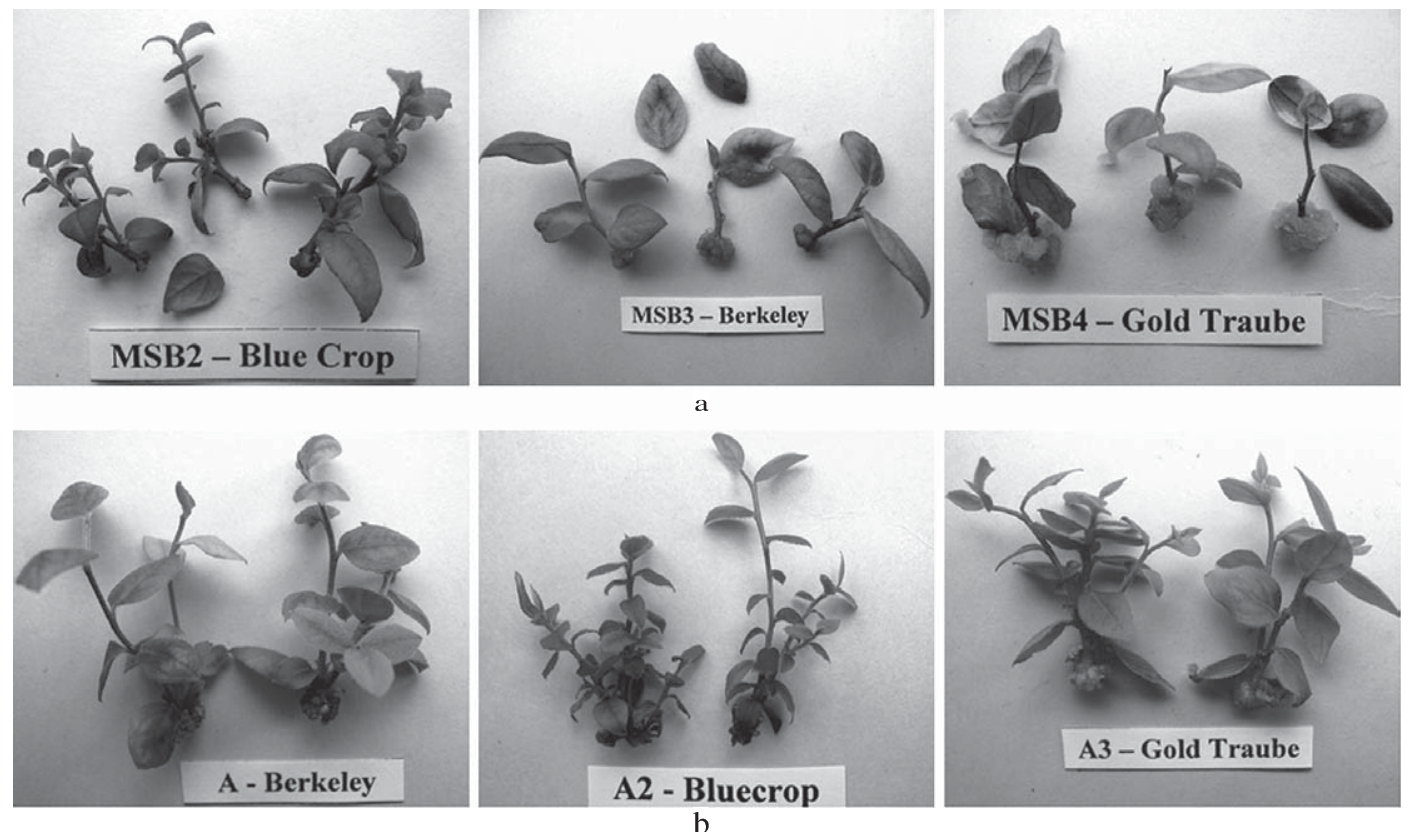

Fig. 1. Shoots of blueberry cultivars in multiplication stage on two basal nutritive media. (a) MS medium containing $0.5 \mathrm{mg} 1^{-1}$ zeatin combined with IBA at $0.1 \mathrm{mg}^{-1}$ (left), $1 \mathrm{mg}^{-1}$ (middle) and $5 \mathrm{mg} \mathrm{l}^{-1}$ (right). (b) Modified AN medium containing $0.5 \mathrm{mg} 1^{-1}$ zeatin alone (left) or combined with IBA at $0.1 \mathrm{mg}^{-1}$ (middle) and $1 \mathrm{mg} \mathrm{l}^{-1}$ (right).

latter proved to be more suitable for micropropagation of highbush blueberry cultivars 'Spartan', 'Bluecrop' and 'Berkeley' in comparison with AN medium and half-strength MS medium [23]. In contrast, Tetsumura et al. [10] showed that during the multiplication stage shoots on WPM medium showed poorer growth than those grown either on MS medium or on mixture of equal parts of MS and WPM media. In their experiment, shoots on MS medium grew well but tended towards hyperhydricity, probably due to a high concentration of ammonium ions in this medium [10]. Although no symptoms of hypehydricity were observed in the present experiment, partial or full necrosis of stems and leaves was detected on MS media, and was more pronounced on those containing zeatin combined with increasing concentrations of IBA (Fig. 1a). The highest percentage of necrotic shoots (80\%) was noticed in 'Goldtraube' on MS medium containing 1 and $5 \mathrm{mg}^{-1}$ IBA combined with $0.5 \mathrm{mg} 1^{-1}$ zeatin (Fig. 1a). Additionally, higher concentrations of IBA in MS medium completely inhibited shoot multiplication and significantly decreased length of axial and lateral shoots in all the cultivars (Table 1). Viable shoots were yellowish green with appearance of reddish colouring along leaf edges and stems of lateral shoots. Although Tetsumura et al. [10] associated red shoots in blueberry cultivars grown on WPM medium with nitrogen deficiency we observed identical symptoms on shoots grown on MS medium which contains four times as much nitrogen as WPM. Blueberry shoots on mAN in our experiment also showed red colouring but it was less pronounced, especially in 'Goldtraube'.

Modified AN medium was superior in shoot multiplication, elongation and quality of shoots in all the cultivars (Fig. 1b). Shoots multiplied on medium containing zeatin alone were green and had small, firm, light green callus, while adding IBA at 0.1 and $1 \mathrm{mg} \mathrm{l}^{-1}$ resulted in well developed, light green shoots which, however, exhibited more pronounced red colouring of leaves and stems. Significant differences in multiplication parameters were also observed among media with different hormonal composition (Table 1). As for 'Berkeley' and 'Bluecrop', the medium containing zeatin combined with $0.1 \mathrm{mg} \mathrm{l}^{-1}$ IBA gave higher shoot multiplication rate than the multiplication medium with zeatin alone. Multiplication capacity of 'Goldtraube' on media containing zeatin combined with 0.1 and $1 \mathrm{mg} \mathrm{l}^{-1}$ IBA was similar to that obtained on medium with zeatin alone. Also, adding 0.1 and $1 \mathrm{mg} 1^{-1}$ IBA significantly increased the length of axial shoots in all the cultivars. The same tendency was observed in length of 
Table 2

Rooting parameters in different blueberry cultivars on modified AN medium supplemented with $0.8 \mathrm{mg}^{-1}$ IBA and $4 \mathrm{~g}^{-1}$ activated charcoal

\begin{tabular}{lcccc}
\hline Cultivar & $\begin{array}{c}\% \text { of } \\
\text { rooting }\end{array}$ & $\begin{array}{c}\text { Average no. of roots } \\
\text { per rooted shoot }\end{array}$ & $\begin{array}{c}\text { Average length } \\
\text { of roots }(\mathrm{cm})\end{array}$ & $\begin{array}{c}\text { Average height } \\
\text { of rooted shoots }(\mathrm{cm})\end{array}$ \\
\hline 'Berkeley' & $10.0 \mathrm{c}^{1}$ & $1.0 \mathrm{~b}$ & $1.15 \mathrm{a}$ & $2.35 \mathrm{~b}$ \\
'Bluecrop' & $39.1 \mathrm{~b}$ & $1.3 \mathrm{~b}$ & $1.04 \mathrm{a}$ & $2.87 \mathrm{a}$ \\
'Goldtraube' & $81.8 \mathrm{a}$ & $2.6 \mathrm{a}$ & $1.06 \mathrm{a}$ & $2.37 \mathrm{~b}$ \\
\hline
\end{tabular}

${ }^{1}$ Mean values of rooting parameters within each column followed by the same letter are not significantly different according to Duncan's Multiple Range Test $(P<0.05)$. Data presented in the form of percentage were subjected to arcsine transformation.

lateral shoots. IBA supplemented at $1.16 \mathrm{mg}^{-1}$ significantly enhanced elongation of axillary shoots of highbush blueberry Vaccinium x covilleanum But. et PI 'Herbert' [17]. On the other hand, further increase in IBA concentration to $5 \mathrm{mg}^{-1}$ in our experiments significantly decreased shoot multiplication rate in all the cultivars, bringing about the formation of low-quality shoots with chlorotic leaves and huge calli. The occurrence of shoot tip necrosis was also observed.

These results suggest that AN medium containing zeatin at $0.5 \mathrm{mg}^{-1}$ combined with low concentration of IBA $\left(\leq 1 \mathrm{mg}^{-1}\right)$ can be successfully used in micropropagation of the three highbush blueberry cultivars. Numerous studies have demonstrated that zeatin is an important plant growth regulator for efficient multiplication and growth in Vaccinium spp. Zeatin was found to be more effective than other cytokinins (e.g. 2iP) for shoot initiation in eight of twelve Vaccinium genotypes [7] as well as for axillary shoot proliferation and adventitious regeneration of highbush blueberry [2] and lingonberry (V. vitis-idea) [24]. Although very high concentration of zeatin $\left(10-20 \mathrm{mg} \mathrm{l}^{-1}\right)$ was found most effective for shoot proliferation of highbush blueberry [6], Gajdošova et al. [2] pointed out the effectiveness of zeatin at low concentration $\left(0.5 \mathrm{mg} \mathrm{l}^{-1}\right)$ for inducing multiple shoot formation in meristem cultures of Vaccinium spp. Also, low concentrations of zeatin $(0.2-1.3 \mathrm{mg}$ $1^{-1}$ ) were successfully applied to develop an efficient cranberry (Vaccinium macrocarpon Ait.) cloning protocol that enables shoot proliferation and rooting in one step [25]. However, the effect of different auxins on shoot multiplication of Vaccinium spp. has been given little attention. Gonzalez et al. [8] found that adding IAA at $0.65 \mathrm{mg}^{-1}$ into medium supplemented with $2 \mathrm{iP}$ did not significantly affect multiplication and elongation of shoots of highbush blueberry 'Berkeley'. On the other hand, the study of Litwinczuk and Wadas [17] revealed that IBA combined with cytokinin can facilitate micropropagation of highbush blueberry 'Herbert' through axillary shoots, as it reduces development of adventitious shoots. However, IBA was found to cause more frequent dying or callusing of explants and to occasionally weaken proliferation of axillary shoots, thus decreasing the efficiency of micropropagation [18], which was confirmed in our experiments only at high concentrations of IBA $\left(5 \mathrm{mg} \mathrm{l}^{-1}\right)$.

In vitro rooting of blueberry has been little described so far. Eccher and Noe [6] used quick dipping treatment of highbush blueberry shoots in IBA solution followed by growth on hormone-free medium. Rooting can also be induced in the shoot proliferation medium without plant growth regulators [10] or in medium containing IBA or NAA [14, 15, 23]. In this study we examined the effect of IBA and active charcoal at constant concentration on induction of rhizogenesis in different cultivars. Rooting capacity of shoots varied greatly among the tested blueberry cultivars (Table 2). The modified AN medium supplemented with $0.8 \mathrm{mg}^{-1}$ IBA and $4 \mathrm{~g}^{-1}$ activated charcoal was the most effective for root induction in 'Goldtraube'. The rooting rate in this cultivar (81.8\%), along with most of the other rooting parameters, was significantly higher than in those obtained for 'Berkeley' and 'Bluecrop', being $10 \%$ and $39.1 \%$, respectively. In all the cultivars, IBA promoted development of roots directly from the basal section of shoots, without callus formation (Fig. 2a, b). Sedlak and Paprstein [23] reported similar effect of this auxin on direct root induction, but much higher rooting rates in 'Berkeley' and 'Bluecrop' on WPM medium supplemented with $1 \mathrm{mg} \mathrm{l}^{-1}$ IBA. 


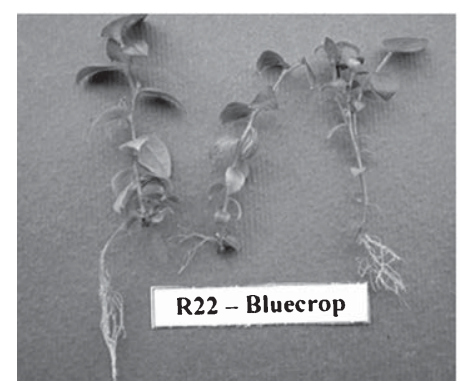

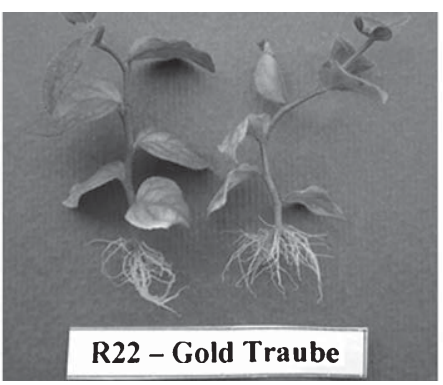

b

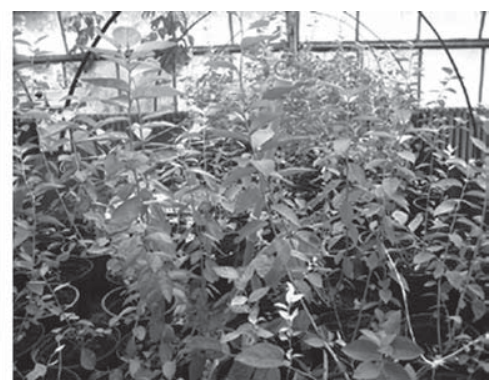

Fig. 2. In vitro rooted shoots of 'Bluecrop' (a) and 'Goldtraube' (b). Adapted blueberry plants in greenhouse one year upon acclimatization (c).

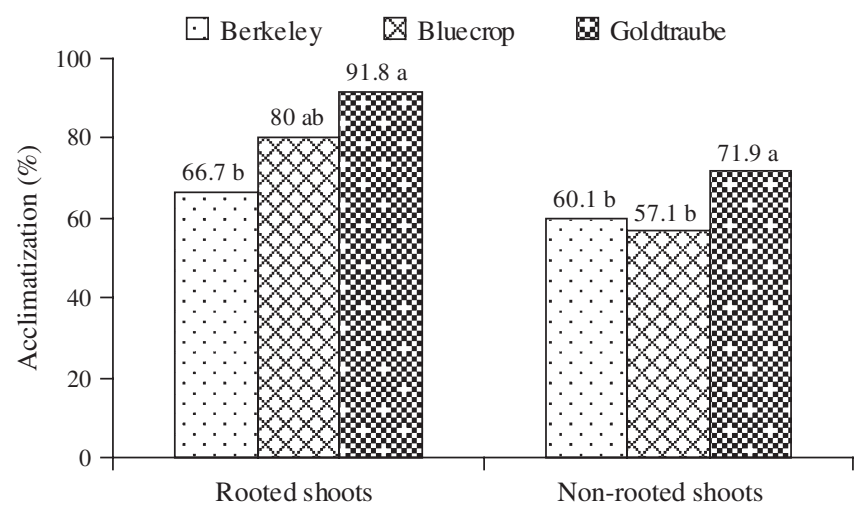

Fig. 3. The comparison of acclimatization rates in both rooted and non-rooted shoots of blueberry cultivars. Values within each category of shoots followed by the same letter are not significantly different $(P<0.05)$ according to Duncan's Multiple Range Test (data were subjected to arcsine transformation).

The acclimatization was monitored two weeks upon transferring both in vitro rooted and non-rooted plants to ex vitro conditions (Fig. 2c and 3). As regards rooted shoots, the acclimatization rate was the highest in 'Goldtraube' (91.8\%), and the lowest in 'Berkeley' (66.7\%). This tendency was observed in acclimatization of non-rooted shots, although the acclimatization rates were considerably lower, especially in 'Bluecrop' and 'Goldtraube'.

\section{Conclusions}

These studies reveal that nutrient media have critical impact on multiplication and growth of highbush blueberries 'Berkeley', 'Bluecrop' and 'Goldrtaube'. MS medium cannot be used for blueberry micropropagation due to the

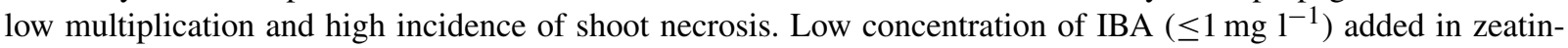
supplemented AN medium increases shoot multiplication efficiency of highbush blueberries in vitro and can be recommended for large-scale propagation of high quality plants. As regards rooting, further research is required to improve in vitro rooting potential of 'Berkeley' and 'Bluecrop' shoots. 


\section{Acknowledgments}

The paper has been implemented in the framework of an intergovernmental programme between Serbia and Slovakia (project: In vitro regeneration of highbush blueberry (Vaccinium corymbosum), determination of the genetic variability and development of in vitro transformation protocols) and has been supported by Ministry of Science and Technological Development of the Republic of Serbia, project No. TR-20013A and TR-31064.

\section{References}

[1] A.B. Howell, Update on health benefits of cranberry and blueberry, Acta Hort 810 (2009), 779-785.

[2] A. Gajdošova, M.G. Ostrolucka, G. Libiakova, E. Ondruškova and D. Šimala, Microconal propagation of Vaccinium sp. and Rubus sp. and detection of genetic variability in culture in vitro. J Fruit Ornam Plant Res 14 (2006), 103-119.

[3] A. El-Shiekh, D.K. Wildung, J.J. Luby, K.L. Sargent and P.E. Read, Long-term effects of propagation by tissue culture or softwood single-node cuttings on growth habit, yield, and berry weight of 'Northblue' blueberry, J Amer Soc Hort Sci 121(2) (1996), 339-342.

[4] S.C. Debnath, Strategies to propagate Vaccinium nuclear stocks for the Canadian berry industry, Can J Plant Sci 87 (2007), 911-922.

[5] P.M. Lyrene, Micropropagation of rabbiteye blueberries, HortScience 15 (1980), 80-81.

[6] T. Eccher and N. Noe, Comparison between $2 \mathrm{iP}$ and zeatin in the micropropagation of highbush blueberry (Vaccinium corymbosum L.), Acta Hort 241 (1989), 185-190.

[7] B.M. Reed and A. Adbelnour-Esquivel, The use of zeatin to initiate in vitro cultures of Vaccinium species and cultivars, HortScience 26(10) (1991), 1320-1322.

[8] M.V. Gonzalez, M. Lopez, A.E. Valdez and R.J. Ordas, Micropropagation of three berry fruit species using nodal segments from fieldgrowing plants, Ann Appl Biol 137 (2000), 73-78.

[9] M.G. Ostrolucka, A. Gajdošova and G. Libiakova, Influence of zeatin on microclonal propagation of Vaccinium corymbosum L. Propag Ornam Plants 2 (2002), 14-18.

[10] T. Tetsumura, Y. Matsumoto, M. Sato, C. Honsho, K. Yamashita, H. Komatsu, et al., Evaluation of basal media for micropropagation of four blueberry cultivars, Sci Hortic 119 (2008), 72-74.

[11] Y. Jiang, H. Yu, D. Zhang, S. He and C. Wang, Influences of media and cytokinins on shoot proliferation of 'Brightwell' and 'Choice' blueberries in vitro, Acta Hort $\mathbf{8 1 0}$ (2009), 581-586.

[12] X. Cao and F.A. Hammerschlag, A two-step pretreatment significantly enhances shoot organogenesis from leaf explants of highbush blueberry cv. Bluecrop, HortScience 37(5) (2002), 819-821.

[13] G.Q. Song and K.C. Sink, Agrobacterium tumefaciens-mediated transformation of blueberry (Vaccinium corymbosum L.), Plant Cell Rep 23 (2004), 475-484.

[14] M.G. Ostrolucka, A. Gajdošova, G. Libiakova, K. Hrubikova and M. Bežo, Protocol for micropropagation of selected Vaccinium spp. In: Jain SM, Haggman H, editors. Protocols for Micropropagation of Woody Trees and Fruits. Springer, (2007), p. 445-455.

[15] J. Meiners, M. Schwab and Szankowski I, Efficient in vitro regeneration systems for Vaccinium species, Plant Cell Tiss Org 89 (2007), $169-176$.

[16] J.J. Frett and J.M. Smagula, In vitro shoot production of lowbush blueberry, Can J Plant Sci 63 (1983), 467-472.

[17] W. Litwinczuk and M. Wadas, Auxin-dependent development and habituation of highbush blueberry (Vaccinium x civilleanum But. et PI.) 'Herbert' in vitro shoot cultures, Sci Hortic 119 (2008), 41-48.

[18] W. Litwinczuk and M. Wadas-Boron, Development of highbush blueberry (Vaccinium corymbosum hort. non L.) in vitro shoot cultures under the influence of melatonin. Acta Sci Pol 8(3) (2009), 3-12.

[19] T. Murashige and F. Skoog, A resived medium for rapid growth and bioassays with tobacco tissue cultures, Physiol Plantarum 15 (1962), 473-497.

[20] W.C. Anderson, Tissue culture propagation of red and black raspberries, Rubus idaeus and R. occidentalis, Acta Hort 112 (1980), $124-132$.

[21] S.C. Debnath, Propagation and cultivation of Vaccinium species and less known small fruits, Latvian Journal of Agronomy 12 (2009), 22-29.

[22] Z. Zhang, H. Liu, L. Wu and Y. Li, Technical system of blueberry micropropagation in China, Acta Hort 715 (2006), $421-426$.

[23] J. Sedlak and F. Paprstein, Micrropropagation of highbush blueberry cultivars, Latvian Journal of Agronomy 12 (2009), $108-113$.

[24] S.C. Debnath and K.B. McRae, In vitro culture of lingonberry (Vaccinium vitis-idaea L.): The influence of cytokinins and media types on propagation, Small Fruits Rev 1 (2001), 3-19.

[25] S.C. Debnath, Zeatin-induced one-step in vitro cloning affects the vegetative growth of cranberry (Vaccinium macrocarpon Ait.) micropropagules over stem cuttings, Plant Cell Tiss Org 93 (2008), 231-240. 